\title{
Freqüência e implicações dos auto-anticorpos em hepatites agudas virais
}

\author{
Frequency and implications of autoantibodies in acute viral hepatitis
}

\author{
Liana Codes', Rogério Santos de Jesus', Simone Cunha1, \\ Marla $\mathrm{Cruz}^{2}$ e Raymundo Paraná ${ }^{3}$
}

\begin{abstract}
Resumo Existem interações entre viroses hepatotrópicas e o sistema imunológico do hospedeiro que podem influenciar na patogenicidade da agressão hepática. O objetivo deste trabalho foi investigar a freqüência de auto-anticorpos na fase aguda da hepatite viral, sua relação com atividade bioquímica, gravidade da doença e cronicidade. Foram estudados 156 pacientes com hepatite aguda viral de 1992 a 2000. Destes, 32\% tiveram infecção por vírus $A, 31 \%$ por vírus $B, 8 \%$ por vírus $C, 3 \%$ tiveram hepatite $E$ e $24 \%$ não $A-E$. Na fase aguda, $20,5 \%$ apresentaram FAN e 14,8\% antimúsculo liso positivos. Na convalescença, $6,4 \%$ persistiram com $F A N$ e $3,9 \%$ com antimúsculo liso positivos. Pacientes que persistiam com anticorpos detectáveis não apresentavam níveis de transaminases e bilirrubinas significativamente diferentes daqueles com auto-anticorpos negativos. Concluindo, os anticorpos que aparecem na fase inicial da infecção são transitórios e não têm implicação prognóstica.
\end{abstract}

Palavras-chaves: Hepatite viral. Auto-anticorpos. Prognóstico. Bioquímica.

\begin{abstract}
There are interactions between hepatotropic viruses and the host immune system, which could contribute to liver damage in viral hepatitis. The aim of this study was to investigate the frequency of autoantibodies in patients with acute viral hepatitis and their relationship with biochemical activity, severity of acute illness and chronicity rate. From 1992 to 2000, 156 patients with acute viral hepatitis were enrolled in a prospective study. Among these, hepatitis A was detected in 32\%, hepatitis B in $31 \%$, hepatitis C in $8 \%$, hepatitis E in $3 \%$ and $24 \%$ were considered non A-E hepatitis. During the acute phase, $20.5 \%$ of patients presented ANA and $14.8 \%$ antismooth muscle antibody positive. During convalescence, $6.4 \%$ of patients showed ANA and 3.9\% anti-smooth muscle positive. Comparison between autoantibodies-positive and negative groups showed no differences regarding ALT and bilirubin levels. In conclusion, autoantibodies can occur in acute viral hepatitis but there are no prognostic consequences.
\end{abstract}

Key-words: Viral hepatitis. Autoantibodies. Prognostic. Biochemistry.

A agressão hepática por auto-imunidade é um fenômeno reconhecido em várias doenças do fígado, inclusive naquelas de etiologia viral. Além do agente agressor e de sua interação com o sistema imunológico do hospedeiro, fatores ambientais ou hormonais estão aparentemente envolvidos no surgimento de autoimunidade hepática, como se supõe acontecer na hepatite auto-imune em indivíduos geneticamente suscetíveis.

A lesão hepatocelular relacionada a infecção pelos vírus hepatotrópicos e pelos herpes vírus (citomegalovírus e Epstein-Barr) é secundária a uma resposta auto-imune do hospedeiro. Estes vírus não parecem ser diretamente citopáticos, mas desencadeiam lesão hepática através da resposta imune do hospedeiro contra células hepáticas infectadas ${ }^{9}$.

O conceito de auto-imunidade induzida por vírus não é exclusivo para doenças hepáticas. O vírus Coxsackie do grupo B é responsável por mais de um terço dos casos clínicos de miocardite infecciosa e está implicado nas miocardites auto-imunes, reagindo contra a miosina cardíaca ${ }^{4}$. Niwa et $a^{13}$ encontraram elevação transitória de auto-anticorpos, incluindo fator reumatóide, fator

\footnotetext{
1. Curso de Pós-Graduação em Medicina e Saúde da Universidade Federal da Bahia. 2. LEME Laboratório-Salvador, BA. 3. Serviço de Gastro-Hepatologia do Hospital Universitário Professor Edgard Santos, Salvador, BA

Trabalho obteve financiamento do CADCT, Secretaria de Planejamento Ciência e Tecnologia do Estado da Bahia e do CNPq, através de Bolsa IC, $P Q$.

Endereço para correspondência: Dra. Liana Codes. Av. Juracy Magalhães Jr 2096, sala 510, 41920-000 Salvador, BA.

Tel: 71 350-4651, Fax:71 353-4980.

e-mail:unif@svn.com.br

Recebido para publicação em 24/08/2001.
} 
antinúcleo, anticorpo anti-DNA (títulos acima de 1:40) em doenças virais comuns como: varicela, sarampo, influenza, caxumba, herpes zoster e exantema súbito ${ }^{13}$.

Existem estudos que focalizam alterações imunológicas em hepatites virais, entretanto a maioria deles mostra resultados pontuais, sem seguimento na fase aguda da doença ${ }^{2}{ }^{11}$. Além disso, ainda não se estabeleceu uma associação entre as reações autoimunes transitórias induzidas por viroses hepatotrópicas e agravamento do dano tecidual na hepatite viral.

O objetivo deste estudo foi investigar a freqüência de auto-anticorpos na fase aguda da hepatite viral, sua relação com atividade bioquímica e gravidade da doença, além de relação com cronificação no caso de vírus $\mathrm{B}$ e $\mathrm{C}$.

\section{MATERIAL E MÉTODOS}

De 1992 a 2000, 156 pacientes, com hepatite aguda viral (HAV), atendidos em ambulatório de hepatologia da Universidade Federal da Bahia, referência para a cidade de Salvador, foram selecionados. Os pacientes foram seguidos por 6 meses, definindo-se como cronificação a persistência de aminotransferases alteradas e/ou HCV-RNA positivo e/ou Ag HBs positivo após este período de seguimento.

O diagnóstico de HAV foi considerado por critérios clínicos (sintomas prodrômicos seguidos ou não por icterícia), provas bioquímicas (elevação de ALT maior que dez vezes o limite superior do normal) e testes sorológicos (IgM anti-VHA, AgHBs, IgM anti- HBc, antiVHC, anti-VHE), utilizando-se kits comerciais da Abbott (Chicago, IL).

O diagnóstico de infecção aguda pelo vírus da Hepatite C foi confirmado pela presença do HCV-RNA ${ }^{7}$ e ou seroconversão anti-HCV, além da histopatologia. Foram incluídos pacientes com hepatite aguda viral não A-E, nos quais infeção pelo CMV e EBV foram afastadas por sorologia especifica, IgM anti-EBV e IgM anti-CMV (Biomerieux, Lyon France).

Os pacientes com relato de uso de drogas hepatotóxicas nos últimos 90 dias, obstrução biliar, insuficiência cardíaca congestiva, uso de álcool acima de 40 gramas de etanol ao dia e com outras possíveis causas de agressão hepática aguda foram excluídos.

Testes bioquímicos (aminotransferases, fosfatase alcalina, gama-glutamiltransferase, tempo de protrombina e bilirrubinas totais) foram realizados na fase aguda e a cada quinze dias durante três meses. A partir deste período, as análises foram realizadas mensalmente até o sexto mês.

Auto-anticorpos (FAN e antimúsculo liso) foram determinados por imunofluorescência indireta durante a fase aguda e repetidos com 30 e 90 dias $^{8}$.

O estudo foi aprovado pelo Comitê de Ética do Hospital Universitário Prof. Edgard Santos.

Análise estatística: Os resultados foram descritos sob a forma de números absolutos e percentuais, com uso de medidas de tendência central e de dispersão quando apropriado. Variáveis dicotômicas foram analisadas através do qui-quadrado ou teste de Fisher quando necessário. A comparação de médias foi feita com o teste de Mann-Whitney. Utilizou-se o software SPSS (windows 9.01) para a análise da estatística e alfa de 0,05 (teste bicaudal) para considerar significância estatística.

\section{RESULTADOS}

Dos 156 pacientes incluídos no estudo, 69 (44,2\%) eram mulheres e $87(55,8 \%)$ homens, com média de idade de $27,6( \pm 14,2)$ anos.

A hepatite por vírus $A$ foi diagnosticada em 51 $(32,7 \%)$ pacientes, por vírus B em $49(31,4 \%)$, por vírus C em $13(8,3 \%)$ e hepatite aguda não A-E em $38(24,4 \%)$ pacientes. O anti-VHE IgG foi encontrado em 5 (3,2\%) dos pacientes, sugerindo a possibilidade desta etiologia; entretanto, o anti-VHE IgM estava positivo em apenas 3 casos.

Durante a fase aguda (primeiros 15 dias), as médias de ALT e bilirrubina total foram respectivamente 1538 $( \pm 1196)$ e $4,2( \pm 4,6)$. Nesta fase, $32(20,5 \%)$ pacientes apresentaram FAN positivo (padrão homogêneo, $\geq 1: 40$ ) e $23(14,8 \%)$ tiveram antimúsculo liso em títulos $\geq 1: 40$ (Figuras 1 e 2).

Utilizamos o teste de Mann-Whitney para comparar médias de transaminases e bilirrubinas na fase aguda entre pacientes com anticorpos positivos e negativos, mas não encontramos diferenças estatisticamente significantes. As Figuras 3 e 4 demonstram o comportamento de transaminases (ALT) e bilirrubinas totais na fase aguda e na convalescença nos grupos de pacientes com anticorpos positivos e negativos (FAN). Não foram encontradas diferenças em relação à presença ou ausência de autoanticorpos.

$\mathrm{Na}$ fase de convalescença (90dias), apenas 10 $(6,4 \%)$ pacientes apresentavam FAN em títulos baixos $(\leq 1: 40)$ e $6(3,9 \%)$ apresentavam antimúsculo liso positivo $(\leq 1: 40)$.

Os pacientes que persistiam com anticorpos detectáveis não apresentavam níveis de transaminases e bilirrubinas significativamente diferentes dos pacientes que negativaram os anticorpos. Também não houve diferença quanto ao sexo e faixa etária quando os pacientes com e sem anticorpos positivos foram comparados. 

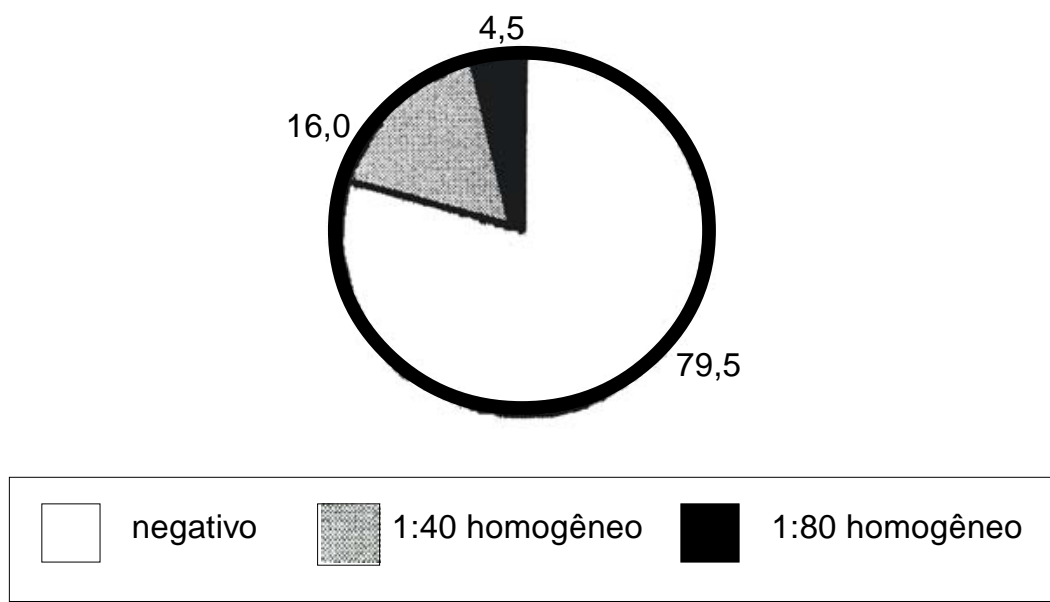

Figura 1 - Distribuição de freqüências de FAN na fase aguda das hepatites (\%).

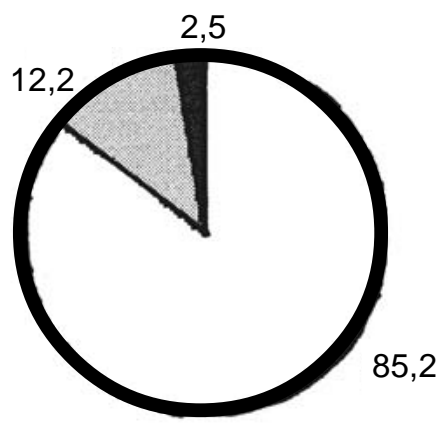

\section{negativo}

Figura 2 - Distribuição de freqüências de $A M L$ na fase aguda das hepatites (\%).

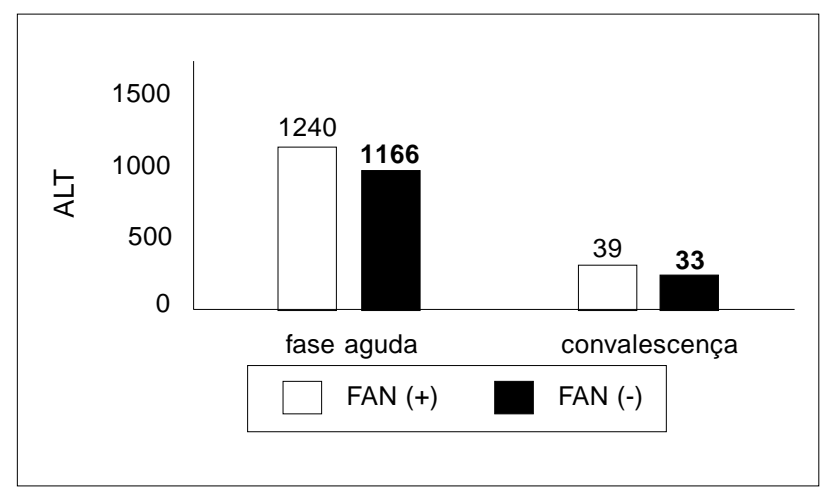

Figura 3 - Comparação dos níveis de transaminases( $A L T)$ na fase aguda e convalescença de acordo com FAN (valores expressos em medianas).

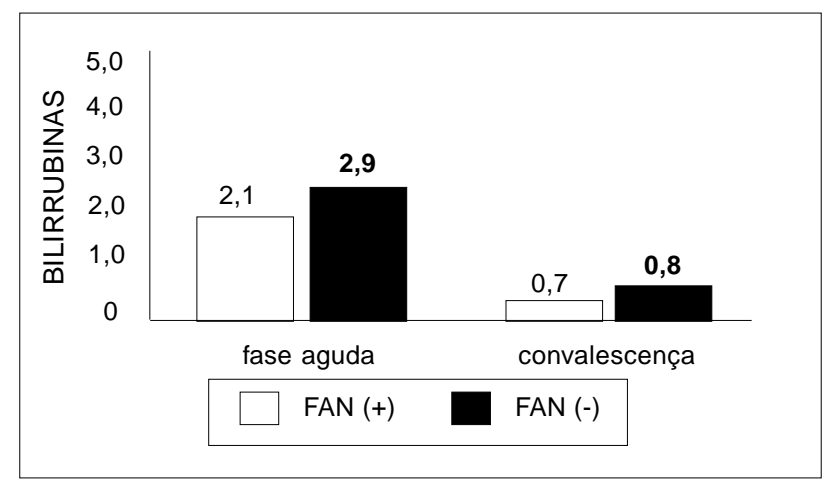

Figura 4 - Comparação dos níveis de bilirrubinas totais na fase aguda e convalescença de acordo com FAN (valores expressos 


\section{DISCUSSÃO}

Existem interações complexas entre os vírus hepatotrópicos e o sistema imunológico do hospedeiro cujas conseqüências podem ser potencialmente danosas para o hospedeiro, contudo as reações auto-imunes transitórias, com formação de auto-anticorpos não órgãoespecíficos, induzidas por vírus hepatotrópicos, não parecem estar associadas ao agravamento do dano tecidual na hepatite aguda viral.

A formação dos auto-anticorpos parece ser mais uma conseqüência do que uma causa da agressão hepática. Os vírus podem causar modificação de autoantígenos ou alterarem sua apresentação ao sistema imune do hospedeiro, induzindo a formação dos autoanticorpos como conseqüência da liberação de componentes celulares que não seriam normalmente expostos ao sistema imunologico do hospedeiro.

Por outro lado, antigenos virais são expressos nas superfícies celulares e desencadeiam respostas antivirais, assim como reações imunes contra autoantígenos que partilham semelhanças com antigenos virais. Os vírus podem ainda modificar proteínas do hospedeiro, de forma a torná-las imunogênicas, ativando o sistema imunológico e causando auto-reação ${ }^{10}$.

Disfunções no controle da auto-imunidade podem ocorrer durante uma infecção viral, com proliferação de subpopulações de linfócitos T ou B e inibição de células $T$ regulatórias. Mediadores inflamatórios como o interferon e interleucinas atraem e estimulam células apresentadoras de antígenos, ativam células T, aumentam a expressão de antígenos de histocompatibilidade em superfícies celulares, facilitando a ocorrência de reações auto-imunes.

Nas Infecções agudas, espera-se que a resposta auto-imune diminua à medida que os vírus são eliminados. Entretanto, alguns trabalhos sugerem que em indivíduos geneticamente susceptíveis, as reações auto-imunes possam persistir apesar do clareamento viral uma vez que o gatilho imunológico foi ativado e não houve desativação ${ }^{510}$.

A presença transitória de auto-anticorpos já foi descrita em doenças virais comuns. Entretanto a associação entre a presença de auto-anticorpos e a gravidade das doenças carece de comprovação.

Neste estudo, os auto-anticorpos estiveram presentes em baixos títulos na fase aguda e caíram rapidamente, retornando ao normal em 30 dias na maioria dos pacientes. A presença dos auto-anticorpos não esteve relacionada com a gravidade da doença quando se levou em consideração o padrão bioquímico. De forma semelhante, a presença dos auto-anticorpos não pareceu influenciar no risco de cronificação da hepatite B, C e Não A-E.

Anteriormente, Lopez e cols ${ }^{7}$ demonstraram presença de anticorpo anti-actina, em baixos títulos, em crianças com hepatite aguda A, por curto período de tempo, porém nenhuma associação com gravidade da agressão hepática fora descrita ${ }^{6}$.

$\mathrm{Na}$ hepatite aguda viral pelo VHA, respostas autoimunes podem ser demonstradas através de altos títulos de anticorpo contra proteína especifica do fígado (antiLSP) na fase inicial de doença, entretanto ainda não se confirmou a relação entre a presença deste auto-anticorpo e lesão tecidual. A presença do anticorpo antimúsculo liso também foi descrito neste estudo, enquanto o anticorpo anti-receptor de asialoglicoproteina (anti- ASGP-R) ocorre menos freqüentemente e em baixos títulos. Essas reações auto-imunes podem contribuir para o dano hepatocelular, mas correlações com os aspectos histopatológicos ainda não foram descritas ${ }^{1016}$.

As lesões hepatocelulares que ocorrem em infecções pelo vírus B são decorrentes de respostas imunes contra células infectadas. Muitos pacientes com hepatite aguda B apresentam anti-LSP circulante e, menos freqüentemente, estes pacientes expressam anti-ASGP-R ${ }^{18}$. Levando-se em consideração a ausência de patogenicidade direta do VHB no hepatocito do hospedeiro, deve-se supor alguma importância de mecanismos de auto-agressão ao fígado, contribuindo para o dano tecidual. Auto-anticorpos transitórios, em baixos títulos, contra músculo liso, endotélio vascular, núcleo e antígenos de membrana são também detectados em fase aguda da hepatite $B$.

Segundo Berg e cols ${ }^{1}$, a ocorrência destes autoanticorpos indicaria um prognóstico desfavorável ${ }^{1}$. Perperas e cols ${ }^{15}$ sugeriram que os auto-anticorpos poderiam estar envolvidos na progressão ou no desenvolvimento de hepatites crônicas, possivelmente por um distúrbio no controle da auto-reatividade ${ }^{15}$. Outros estudos questionam a participação dos autoanticorpos no processo de transição para cronicidade das hepatites agudas virais, porem os resultados não são convincentes ${ }^{12}$.

Brown e cols ${ }^{3}$ demonstraram que o soro de pacientes com hepatite aguda viral reage com vimentina em extratos de fibroblastos, sugerindo que auto-anticorpos antivimentina estão presentes em hepatites agudas A, $B$ e não $A$ não $B^{3}$.

Passaleva e cols ${ }^{14}$ avaliaram 302 pacientes com hepatites agudas virais e encontraram elevada prevalência de antimúsculo liso no soro de pacientes com hepatite $A$ $(60 \%)$, hepatite $B(51 \%)$ e hepatite não $A$ não $B(21 \%)$, principalmente nas primeiras semanas de doença ${ }^{14}$.

Complexos imunes circulantes (CIC) foram detectados em $51,6 \%$ dos pacientes, com freqüência significativamente maior em hepatite aguda $A$. Nenhuma associação entre a presença de imunocomplexos e o nível de aminotransferases ou bilirrubinas foi encontrada ${ }^{14}$

Em resumo, os resultados em nosso estudo são semelhantes aos descritos por Passaleva e cols ${ }^{14}$. Em 
nossos pacientes, os auto-anticorpos foram mais freqüentes na fase inicial da doença, sua freqüência foi reduzida na fase de convalescença e não encontramos relação entre anticorpos e níveis de aminotransferases e ou bilirrubinas, sugerindo ausência de associação com gravidade de doença. Da mesma maneira não encontramos associação entre a presença de autoanticorpos e cronificação da hepatite viral.
Assim, apesar dos vírus desencadearem autoreatividade , os anticorpos que aparecem na fase inicial da infecção são transitórios e, aparentemente, não estão relacionados à gravidade de doença ou risco de cronificação. Nesta situação, os auto-anticorpos parecem ser mais um epifenômeno da agressão hepatocelular do que um marcador prognóstico com implicações na patogênese da doença.

\section{REFERÊNCIAS BIBLIOGRÁFICAS}

1. Berg PA. Humoral immune phenomena in acute and chronic viral hepatitis. Immunol Infectol 3:172-181, 1975.

2. Block M, Schiano FD. Management of overlap syndromes. In: Decker M (ed) Management of liver disease, New York, p. 170-177, 1999.

3. Brown C, Pedersen J, Underwood JR. Autoantibodies to intermediate filaments in acute viral hepatitis $A, B$ and non $A$ non $B$ are directed against vimentin. Journal of Clinical and Laboratory Immunology 19:1-4, 1986.

4. Gist NR, Bell EJ. A six years study of coxsakievirus B in heart disease. Journal of Hygiene 73:165-171, 1974.

5. Huppertz HI, Treidel U, Gassel AM. Autoimmune hepatitis following hepatitis A virus infection. Journal of Hepatology 23:204-208, 1995.

6. Li JS, Tong SP, Vitvitski L, Trepo C. Single-step nested chain reaction for detection of different genotypes of hepatitis $C$ virus. Journal of Medical Virology 45:151-155, 1995.

7. Lopez SI, Seia J, Roy A. Anti-actin antibodies in acute viral hepatitis A in children. Acta Gastroenterologica Latinoamericana 28:261-264, 1998.

8. Manns M. Cytoplasmic autoantigens in autoimmune hepatitis : Molecular analysis and clinical relevance. Seminars in Liver Disease 11:205 - 214, 1997.
9. Markin RS. Manifestations of Epstein-Barr virus associated disorders in liver. Liver 14:11-13,1994.

10. Mc Farlane. Gl-autoimmunity and hepatotropic viruses. Seminars in Liver Disease 11:223-233, 1991.

11. Mc Farlone IG, Smith HM, Johnson PJ, Bray GP, Vergoni D, William R. Hepatitis $C$ auto-antibodies in chronic active hepatitis. Lancet 335:754-757, 1990.

12. Meliconi R, Baraldini M, Stefanini GF. Antibodies against human liver specific protein (LSP) in acute and chronic viral hepatitis types A, B and non A non B. Clinic and Experimental Immunology 46:382-390, 1981.

13. Niwa Y, Sakane T, Kanoh T. Transient autoantibodies with elevated complement levels in common viral diseases. Journal of Clinical and Laboratory Immunology 13:183-188, 1984.

14. Passaleva A, Massai G, Leoncini F. Acute viral hepatitis in the Florence área: II Immunologic study. Bolletino dell' Instituto Sieroterapico Milanese 62:224-237, 1983.

15. Perperas A, McFarlane BM, McSorley CG. Species cross reactivity of anti LSP antibodies in acute viral hepatitis. Journal of Clinical and Laboratory Immunology 19:25-30, 1986.

16. Vento S, McFarlane BM, McSorley CG. Liver autoreactivity in acute virus $A, B$ and nonA nonB hepatitis. Journal of Clinical and Laboratory Immunology 25:1-7, 1988. 